2000-04-15

\title{
Survey of home infusion care in England
}

\section{Loader, J}

http://hdl.handle.net/10026.1/3739

10.1093/ajhp/57.8.763

American Journal of Health-System Pharmacy

Oxford University Press (OUP)

All content in PEARL is protected by copyright law. Author manuscripts are made available in accordance with publisher policies. Please cite only the published version using the details provided on the item record or document. In the absence of an open licence (e.g. Creative Commons), permissions for further reuse of content should be sought from the publisher or author. 


\title{
Survey of home infusion care in England
}

\author{
JILL LOADER, GRAHAM SEWELL, AND SHIVAUN GAMMIE
}

Am J Health-Syst Pharm. 2000; 57:763-6

The Pharmacy Abroad section of AJHP features brief, informal, and topical communications related to pharmacy in other countries. Contributions are welcomed from pharmacists abroad or from pharmacists who have traveled abroad.

AJHP also encourages pharmacists from outside of the United States to submit traditional manuscripts (e.g., scientific studies, descriptions of practice innovations), which are evaluated for publication in the primary sections of the journal.

$\mathrm{T}$ he National Health Service (NHS) was founded in 1948 by the government of the United Kingdom on the principle that the care it provided would be available to all, irrespective of means, on the basis of need and that most services would be provided free of charge at the point of use. The NHS is funded through national income taxes. Government health policy is implemented through the Department of Health (run by elected officials led by the Minister for Health, who reports directly to the Prime Minister) and is managed by the NHS Executive (run by appointed civil servants). The NHS Executive has eight regional offices that manage the 100 Health $\mathrm{Au}$ thorities (HAs) in England.

During the late 1980s, HAs were given the resources to purchase health care for their local populations. The resources were to cover health promotion, public health, and all health care provided in the community and through hospitals. Providers of health care competed for contracts to deliver their services. (The NHS is currently undergoing a reform that will move responsibility for purchasing health care from the HAs to primary care.)

Physicians (general practitioners, or GPs) and health care professionals working in the community are the public's primary access to health care (primary care). GPs may refer their patients to specialist physicians in hospitals (secondary care), who in turn may seek advice from specialty hospitals (tertiary referral centers).

Acceptance of home infusions has been slow in England because of the way health care is funded through the NHS, the lack of incentives to change current practice, and the existence of other priorities. ${ }^{1}$ There is no direct cost to the patient or an insurer when a patient is admitted to the hospital, and therefore there is no direct financial pressure from them to reduce the length of stay.

Jill LOADER, MRPharmS, is Ph.D. student, Department of Pharmacy and Pharmacology, University of Bath, and Pharmaceutical Advisor, Wiltshire Health Authority, Wiltshire, United Kingdom. Graham SeWEl., Ph.D., MRPharmS is Professor of Clinical Pharmacy and Pharmacy Practice, University of Bath, and Consultant Pharmacist, Plymouth Hospitals NHS Trust, Plymouth, United Kingdom. SHIVAun Gammie, PH.D., MRPHARMS, is Pharmaceutical Advisor,
Before 1995, some GPs prescribed infusions for their patients and some home infusions were organized and paid for via secondary or tertiary care (the hospitals, or NHS trusts). In 1995 , the government issued a directive that instructed HAs to buy packages of care for patients at home whose treatments included "the delivery of drugs together with other products and equipment needed to administer them" (e.g., total parenteral nutrition [TPN], intravenous antimicrobials, and antineoplastic agents). ${ }^{2}$ The HAs contracted only for those patients for whom GPs were previously prescribing drugs; hospitals continued to pay, out of their own budgets, for patients they were already treating with home infusions.

The objective of this study was to collect information on the purchasing and provision of home infusions in England. Specifically, we sought to identify

- The indications for home infusions,

- The number of patients receiving home infusions,

- The contract mechanisms,

- The providers of various elements of home infusion care,

- The geographic distribution of patients receiving home infusions, and

- The mechanisms for monitoring quality and outcomes.

\section{South and West Devon Health Authority, Devon,} United Kingdom.

Address reprint requests to Ms. Loader at Wiltshire Health Authority, Southgate House, Pans Lane, Devizes, SN10 5EQ United Kingdom.

Copyright (c) 2000, American Society of Health-System Pharmacists, Inc. All rights reserved. 1079-2082/00/0402-0763\$06.00. 
Methods. Surveys were conducted of all the purchasers and providers of home infusion care in England for the period from April 1997 to December 1998. We visited regional meetings of pharmaceutical and medical advisers of the $100 \mathrm{HAs}$ to explain the objectives of the project and to distribute written questionnaires on the purchasing of home infusions. We conducted a telephone survey of all the hospitals in England (excluding those specializing in mental health and learning disabilities) to establish which were involved in caring for patients receiving home infusions. This was followed up with a written questionnaire to elicit further information from those who did purchase or provide home infusions for their patients. Finally, we sent a written survey to the six commercial providers of home infusions in England. This questionnaire was designed in conjunction with members of the industry, who advised us on what information the companies might be willing to share in this commercially sensitive area.

The anonymity of all survey participants was ensured to encourage frank reporting.

Results. Indications for home infusions. The main indications for home infusions in England were administration of TPN for Crohn's disease and short-bowel syndrome, antimicrobial agents for cystic fibrosis, antineoplastic agents (continuous infusions), deferoxamine for thalassemia, and antivirals for HIV infection.

Table 1 shows the percentage of responding HAs and hospitals providing home infusions for patients under their jurisdiction. The hospitals were more likely to provide antineoplastic agents and antivirals for HIV infection than the HAs, but the HAs more commonly had contracts for providing home TPN than the hospitals. The reason is probably that fewer GPs were prescribing antineoplastic agents and antivirals for their patients before the 1995 government directive. ${ }^{2}$
Number of patients. In many cases, neither the hospitals nor the HAs were able to specify the number of patients receiving home infusions. While an HA may take on responsibility for contracting for the provision of, for example, home parenteral nutrition for the patients in its area, it may leave the provision of other types of home infusions, such as infusions of antineoplastics or deferoxamine, entirely to the local hospital (Table 1). The HA may not even be aware that patients are being treated at home with such other infusions.

It was not easy to interpret the results for patient numbers. When the question was left blank, this could have meant either (1) that no patients were being treated at home with that drug or for that condition or (2) that the participant did not know if there were any of these patients.

The largest numbers of patients

Table 1.

\section{Percentage of Health Authorities and Hospitals Providing Home Infusions}

\begin{tabular}{|c|c|c|}
\hline \multirow[b]{2}{*}{ Indication } & \multicolumn{2}{|c|}{$\begin{array}{l}\text { No. (\%) Respondents } \\
\text { Providing Home Infusions }{ }^{\text {a }}\end{array}$} \\
\hline & Health Authorities & Hospitals \\
\hline \multicolumn{3}{|l|}{ Administration of antimicrobials for cystic } \\
\hline fibrosis & $40(46.0)$ & $43(45.7)$ \\
\hline Antineoplastic therapy & $5(5.7)$ & $39(41.5)$ \\
\hline Administration of antivirals for HIV infection & $9(10.3)$ & $14(14.9)$ \\
\hline Total parenteral nutrition administration & $47(54.0)$ & $41(43.6)$ \\
\hline Deferoxamine administration & $22(25.3)$ & $30(31.9)$ \\
\hline \multicolumn{3}{|l|}{ Administration of enzymes for Gaucher's } \\
\hline disease & $5(5.7)$ & $5(5.3)$ \\
\hline Administration of immunoglobulins & $2(2.3)$ & $5(5.3)$ \\
\hline Administration of terbutaline & $2(2.3)$ & $2(2.1)$ \\
\hline Pain relief & $0(0)$ & $5(5.3)$ \\
\hline Administration of epoprostenol & $2(2.3)$ & $1(1.1)$ \\
\hline \multicolumn{3}{|l|}{ Administration of antimicrobials for other } \\
\hline & $0(0)$ & $8(8.5)$ \\
\hline
\end{tabular}

Table 2.

Number of Patients Receiving Home Infusions

\begin{tabular}{|c|c|c|c|}
\hline \multirow[b]{2}{*}{ Indication } & \multicolumn{3}{|c|}{ No. Patients ${ }^{a}$} \\
\hline & Health & Authorities & Hospitals \\
\hline Administration of antimicrobials for cystic fibrosis & & 446 & 879 \\
\hline Antineoplastic therapy & & 33 & 990 \\
\hline Administration of antivirals for HIV infection & & 25 & 83 \\
\hline Total parenteral nutrition administration & & 234 & 449 \\
\hline Deferoxamine administration & & 114 & 264 \\
\hline
\end{tabular}

${ }^{a}$ Numbers are normalized (divided by percent response rate and multiplied by 100 ). had their care either supplied or purchased by hospitals (Table 2). The st numbers of patients were remiving antineoplastic agents or antiwewer were receiving home TPN , although the largest exhome TPN.

Contract mechanisms. HAs generally have bulk contracts with local hospitals for providing specified services in order to avoid the large administrative costs of individually billing for every service provided. Less than half (46\%) of the HAs purchased home in(usions under a separate contract. One 作 the hospitals to purch and left it to hospitals to purchase or provide infusions. Fifteen percent used a separate contract for some drug products and a bulk contract for oth(26\%) added the money, taken 
Table 3.

Providers of Specific Elements of Home Infusion Care

\begin{tabular}{|c|c|c|}
\hline \multirow[b]{2}{*}{ Element of Care and Provider } & \multicolumn{2}{|c|}{ No. (\%) Respondents } \\
\hline & Health Authorities & Hospitals \\
\hline \multicolumn{3}{|l|}{ Drugs } \\
\hline Hospital pharmacy & $63(52.5)$ & $160(68.4)$ \\
\hline Commercial company & $53(44.2)$ & $68(29.1)$ \\
\hline Community pharmacy & $0(0)$ & $5(2.1)$ \\
\hline Other & $4(3.3)$ & $1(0.4)$ \\
\hline \multicolumn{3}{|l|}{ Nursing care } \\
\hline Hospital & $22(22.9)$ & $143(62.4)$ \\
\hline Commercial company & $39(40.6)$ & $30(13.1)$ \\
\hline Community hospital or district nurses & $25(26.0)$ & $48(21.0)$ \\
\hline Other & $10(10.4)$ & $8(3.5)$ \\
\hline \multicolumn{3}{|l|}{ Equipment and supplies } \\
\hline Hospital & $35(32.7)$ & $134(61.5)$ \\
\hline Commercial company & $47(47.0)$ & $72(33.0)$ \\
\hline Primary care or community hospital & $13(12.1)$ & $5(2.3)$ \\
\hline Other & $12(11.2)$ & $7(3.2)$ \\
\hline
\end{tabular}

Figure 1. Geographic distribution of patients receiving specified types of home infusions in England.
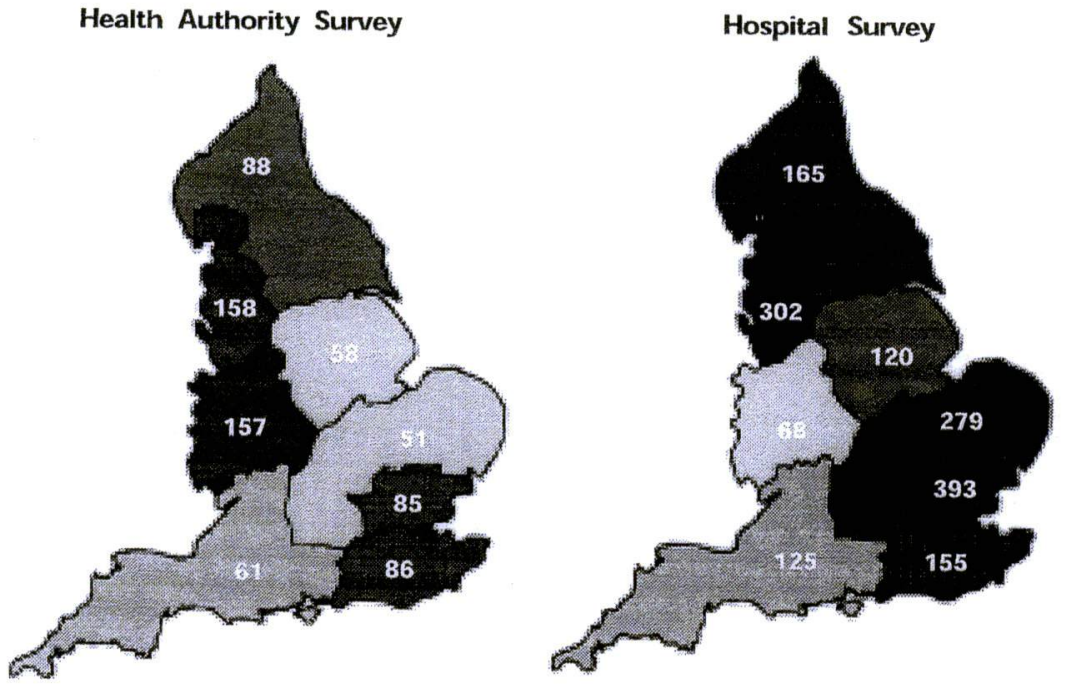

ers. Very few HAs have used bidding for the purchase of home infusions.

Comments submitted by hospital pharmacists indicated that there is a lack of coordination in the hospitals with respect to the purchasing and provision of home infusions. One pharmacist wrote, "The situation is very complex - diffuse and vague accountability - very fragmented. In short, a mess!" Another stated, "I have been trying to find out about cystic fibrosis patients, as I am sure we have some. Unfortunately, I have suppliers of all three when care was purchased or provided by hospitals. Even when the HAs purchased care, the hospitals were still the major providers of drugs and nursing care (closely followed by commercial home care companies); commercial providers most frequently provided equipment and supplies.

The HAs were more likely than the hospitals to purchase a package of care for home infusions from a commercial provider. There was significant input from district nurses (primary care) in providing nursing care for patients receiving home infusions.

Geographic distribution. Figure 1 shows the geographic distribution of patients receiving five specified types of home infusions in the eight regions of the NHS. There was geographic variation in the number of patients being treated with home infusions, and the HAs generally purchased care for fewer patients than the hospitals.

Quality- and outcomes-monitoring initiatives. Twelve HAs expressed concern over the lack of auditing of the quality of patient care, and 11 said they had no way of knowing whether they were getting value for their money. Only 18 (19.1\%) of 94 hospitals said they had an audit system for measuring the quality of care, and only 12 $(12.8 \%)$ had an audit system for measuring patient outcomes.

Five of the six commercial home care providers in England were not aware of any HAs or hospitals with whom they had contracts having any audit systems for measuring patient outcomes or benchmarking their services against those of other providers. Four were aware of contract HAs or hospitals having audit systems for measuring their services against agreed-upon service specifications or for monitoring the services they provided.

One commercial provider stated, "Virtually all our business is noncontractual. Often patients are tendered for individually but in a nonformal 
fashion (i.e., hospitals ring for quotes and usually go for the cheapest!)."

Discussion. Home infusions are gaining acceptance in England, but not uniformly. This may reflect differences in the geographic distribution of the conditions being treated.

There are many mechanisms for purchasing and providing home infusions in England. It is not uncommon for home infusions to be provided on an ad hoc basis. This makes it difficult to obtain a clear and accurate picture of the home infusion market. It was impossible in this study to obtain information from all of the many health professionals who may be involved in the provision of home infusions.

The percentage of HAs providing home infusions was smaller than that found in a telephone survey by other researchers, ${ }^{3}$ possibly because we requested more detailed information in our written survey and because our survey was directed at different professionals within the HAs.

The lack of monitoring of the quality of care received by patients at home and of their clinical outcomes is of concern. Most purchasers are not monitoring their contracts for quality, and providers are not required to demonstrate continuous quality improvement or even a minimum level of service.

The current restructuring of England's NHS creates an opportunity to review the mechanisms used to purchase and provide home infusions. A system whereby all home infusions are purchased via the same mechanism would seem a sensible first step. Quality and outcomes monitoring should be urgently addressed.

Conclusion. A survey of home infusion care in England found deficiencies in coordination of services, quality control, and outcomes monitoring.

\section{References}

1. Nathwani D, Davey P. Intravenous antimicrobial therapy in the community: underused, inadequately resourced, or irrelevant to health care in Britain? BMJ. 1996; 313:1541-3.

2. EL(95)5. Purchasing hi-tech health care for patients at home. Leeds, England: National Health Service Executive; 1995.

3. Short D, Norwood J. Purchasing hi-tech healthcare at home: a report on the implementation of EL(95) 5 by health authorities. Keele, England: University of Keele; 1998. 